\title{
Configurações
}

Revista Ciências Sociais

21 | 2018

Justiça, Instituições, Interlocuções

\section{Limites sociais à liberdade de expressão}

Social limits to free speech

Limites sociales à la liberté d'expression

\section{António Pedro Dores}

\section{OpenEdition}

\section{Journals}

Electronic version

URL: http://journals.openedition.org/configuracoes/5123

DOI: $10.4000 /$ configuracoes.5123

ISSN: 2182-7419

\section{Publisher}

Centro de Investigação em Ciências Sociais

\section{Printed version}

Number of pages: 43-63

ISSN: 1646-5075

\section{Electronic reference}

António Pedro Dores, «Limites sociais à liberdade de expressão », Configurações [Online], 21 | 2018 ,

Online since 30 June 2018, connection on 10 December 2020. URL : http://journals.openedition.org/ configuracoes/5123; DOI : https://doi.org/10.4000/configuracoes.5123 


\title{
Limites sociais à liberdade de expressão
}

\author{
ANTÓNIO PEDRO DORES*
}

CIES-IUL

\section{Resumo}

A sociedade ocidental funda a sua legitimidade no espírito de sacrifício imposto pelo cumprimento da palavra dada e no mérito individual de levar os sacríficos a extremos; no caso dos heróis, dos santos, dos artistas, dos cientistas, dos trabalhadores, dos profissionais, dos dirigentes. $\mathrm{O}$ valor e o significado de um testemunho dependem do lugar social de enunciação. Enunciados por vítimas (ou marginais), os testemunhos são desqualificados. (Des)qualificações sobre as quais elaboram o sistema judicial, o senso comum e as teorias sociais. As ciências sociais, desprendidas duma teoria dos princípios da organização, são metáforas de submissão aos valores dominantes, desqualificando o valor social de experiências não dominantes.

Palavras-chave: violência, organização social, teoria social, discriminação, liberdade de expressão.

\begin{abstract}
Social limits to free speech

Western society bases its legitimacy on the spirit of sacrifice imposed by the practical fulfilment of promises voiced and on the individual merit of carrying out sacrifices to extremes; as in the cases of heroes, saints, artists, scientists, workers, professionals and leaders. The value and meaning of a testimony depends on the social place of enunciation. Stated by victims (or outcasts), the testimonies are disqualified. (Dis)qualifications on which the judicial system, the common sense and the social theories elaborate on. Social sciences, detached from a theory of the principles of organisation, are metaphors of submissiontodominantvalues, disqualifying thesocialvalueofnon-dominantexperiences.
\end{abstract}

Keywords: violence, social organisation, social theory, discrimination, free speech. 


\section{Résumé}

Limites sociales à la liberté d'expression

La société occidentale fonde sa légitimité sur l'esprit de sacrifice imposé par l'accomplissement de la parole donnée et sur le mérite individuel de porter les sacrifices à l'extrême; dans le cas des héros, des saints, des artistes, des scientifiques, des travailleurs et des professionnels. La valeur et la signification d'un témoignage dépendent de la place sociale de l'énonciation. Déclarés par les victimes (ou marginaux), les témoignages sont disqualifiés. (Dé)qualifications sur lesquelles est élaboré le système judiciaire, le bon sens et les théories sociales. Les sciences sociales, détachées d'une théorie des principes d'organisation, sont des métaphores de soumission aux valeurs dominantes, disqualifiant la valeur sociale des expériences non dominantes.

Mots-clés: violence, organisation sociale, théorie sociale, discrimination, liberté d'expression.

\section{Introdução}

"Quem construiu Tebas das setes portas?

Nos livros encontrareis os nomes de reis.

Foram os reis quem arrastou os bocados de rocha?

Para onde foram os pedreiros, quando a muralha da China ficou acabada?"

Bertold Brecht citado por Patricia Fara (2009:41), traduzido por APD

O valor da palavra está na base do contrato. E, este, por sua vez, está na base da individuação (Supiot 2005:137-146). A sociedade ocidental, nestes termos, funda a sua legitimidade no espírito de sacrifício imposto pelo cumprimento da palavra dada e no mérito individual de levar os sacríficos, ao menos simbolicamente, a extremos; como nos casos de heróis, santos, artistas, cientistas, trabalhadores, profissionais, dirigentes.

Em contraponto, a mulher é vista - e continua a ser vista - como improvável heroína, santa, cientista, trabalhadora ou profissional, para não falar de dirigente. Não é necessariamente um processo consciente de discriminação. É o reflexo, tudo o indica, de um modo incorporado milenarmente de imaginar a organização social, diferenciada e hierarquizada em géneros de pessoas. Modo de organização, estrutura social ancestral, suporte básico da civilização, bem marcado pelas religiões do livro, mas ainda por desvendar por uma antropologia jurídica capaz de identificar e explicar a ordem das diferenças de oportunidades entre os que beneficiam dos sacrifícios e os que fazem os sacrifícios.

Como é possível dissimular e desqualificar o valor do trabalho realizado pelas mulheres nos cuidados prestados às diferentes gerações, ou pelos escravos, 
ou pelos assalariados, e sobrestimar o mérito das elites, de forma legitimada, continuada e recorrente?

Esta dissimulação não ocorre apenas na modernidade. Mas a modernidade não está a ser capaz de a erradicar. Uma das razões para essa dificuldade é a superficialidade com que a sociologia tem descrito e criticado a organização social. Em particular, o modo como se tem concentrado nas lutas pelo poder e praticamente abandonado o estudo das lutas pela sobrevivência e pela elaboração de identidades sociais viáveis (Lahire, 2012:125; Therborn, 2006:3). Dito de outro modo, o respeito reverencial e conformista com que as teorias sociais tem aceitado os limites sociais à liberdade de expressão (Scott, 2013).

O valor e o significado de um testemunho dependem do lugar social da enunciação. Enunciados por minorias ou marginais, os testemunhos são desqualificados (Girard, 1972:83-84). (Des)qualificações sobre as quais elaboram o sistema judicial, o senso comum e as teorias sociais, quando trabalham a favor da manutenção e salvaguarda dos princípios de organização social implícitos, arbitrários e estruturantes: princípios de diferenciação de géneros, hierarquização com produção de elites e autonomia do mundo simbólico relativamente ao mundo real. São estruturas ancestrais, denunciadas e atacadas pela modernidade; pelo feminismo, pelos princípios de igualdade e não discriminação, pela ciência. Ao mesmo tempo, a repugnância e as reações conservadoras que tais ataques suscitam têm sido suficientes para que a ordem moderna ideal se mantenha nas mesmas bases civilizacionais das ordens tradicionais. Inegavelmente, as discriminações contra as mulheres e outros géneros de minorias, a favor das elites e dos saberes favoráveis ao status quo (Foucault, 1999b) continuam a prevalecer, espontaneamente, incluindo na mente das próprias vítimas.

As análises de testemunhos de vítimas sobreviventes de um homicídio tentado, de vítimas de violência policial e das limitações ao estudo sociológico das prisões, ilustram efeitos das estruturas sociais que se mobilizam para prevenir os riscos de questionamento dos princípios da organização social.

Em tese, as situações percebidas como pondo em risco esses princípios são alvo privilegiado de segredo, de tabu, de repugnância, que cabe à teoria social des(en)cobrir. Enfrentando, como o fizeram os descobridores, os Adamastores que ameaçam quem se atreva a denunciar que o rei vai nu ou que as discriminações são produções sociais contra as quais se pode lutar. Tal trabalho cognitivo acompanhará a reavaliação dos sacrifícios a que parte importante da população se dedica - prestação de cuidados, solidariedade, trabalhos arriscados, actividades bélicas, etc., assim como as estratégias de enriquecimento desigual à custa da exploração da natureza, incluindo de mão-de-obra, e dos riscos ambientais e sociais implicados (Silva, 2009).

Depois de uma brevíssima referência às discussões sociológicas sobre o que seja a estrutura social, dando conta das dificuldades de explicação da persistência das discriminações sociais, apresenta-se o material empírico sobre o 
qual se vai refletir. A reflexão será conduzida num terreno entre o direito e as teorias sociais - para chamar a atenção da vantagem de as ciências sociais reconhecerem o seu objecto de estudo - a sociedade e a sua organização - como uma característica não exclusiva da modernidade mas, pelo contrário, como algo com raízes profundas nas experiências ancestrais. Tal terreno é triplamente tabu, por pressupor a colaboração entre duas disciplinas, o direito e a sociologia, que de facto não colaboram entre si; por se deter em casos do quotidiano; e por reclamar por uma antropologia jurídica, isto é, o reconhecimento da existência do direito em tempos imemoriais, ancestrais. Por fim, oferecem-se exemplos de diferentes modos como as disposições sacrificiais e o modo como tais disposições são, ao mesmo tempo, mostradas e encobertas por segredos socialmente partilhados.

\section{Estrutura social}

Há diversas maneiras de entender a sociedade. A mais vulgar é a estrutural-funcionalista ou equivalentes: sociedade é diferente dos indivíduos porque quando estes nascem ela já está em pleno funcionamento e nada há que estes possam fazer, a não ser mantê-la a funcionar e a evoluir, sob o risco de se extinguir, caso deixe de funcionar. Cada um no seu lugar, na sua instituição, política, cultural, económica, cumprindo o seu papel de trabalhador ou dirigente, dá o seu contributo, sob a observação de todos os mecanismos sociais e institucionais de controlo e retribuição. Uma outra ideia do que seja sociedade é menos utilizada: a sociedade seria conjunto de selves, produzidos e partilhados por cada um e todas as pessoas com quem se entra em contacto, real ou virtual, ao longo da vida. A primeira sociedade fixa-se na detecção de fronteiras entre os diferentes papéis sociais disponíveis, com que cada ser humano se identifica para efeitos do seu processo de integração social; tipicamente uma auto-definição profissional. A segunda sociedade refere-se aos fluxos de comunicação, trocas económicas, interesse ideológicos, conflitos sociais, produzidos pelos indivíduos ao lutarem para se apresentarem e tornarem pessoas (Blumer, 1981). As diferentes formas de interligar estes dois tipos de concepção de sociedade não têm conseguido ultrapassar as lacunas entre as concepções analíticas de sociedade e as dinâmicas de ação concertada implicando os diversos níveis de realidade social (Mouzelis, 1995:7).

As formas sociológicas de entender sociedade são geralmente eurocentradas; centradas na apresentação da superioridade da modernidade. Presumem a necessidade de um estado nacional para delimitar uma sociedade (Kuhn, 2016). Não atendem à necessidade de criar uma teoria social capaz de compreender, além das formas modernas, as formas tradicionais de organização social produzidas pela espécie humana. 
A estrutura social é frequentemente entendida a partir do modelo institucional ocidental, que pressupõe a autonomia do mundo simbólico relativamente à realidade material. Mas pode ser entendida como o resultado, variável e adaptado, geográfica e historicamente, do desenvolvimento de uma base organizacional ancestral, profunda e arbitrária, essência da civilização, cuja transformação é protegida instintivamente por quem tenha incorporado os princípios dessa civilização (Girard, 1978).

Porque razão as prisões em vez de serem abolidas, como nos anos cinquenta e sessenta se pensava ser o destino do progresso, acabaram por renascer (Wacquant, 2016)? Que forças impedem as mulheres, melhores estudantes, de singrarem na escala do mérito? Por que é as teorias sociais não sabem revelar os mecanismos sociais que sustentam factos tão profundamente desagradáveis e, ao mesmo tempo, aparentemente inelutáveis?

A hipótese apresentada é a seguinte: as sociedades adoptam, arbitrariamente, princípios de organização vernáculos que, uma vez incorporados, se tornam identitários, mesmo no caso dos perdedores. Como bem notam os que se recordam de La Boétie e a sua servidão voluntária; ou os que denunciam a falta atual de oposição política (Marcuse, 1991a).

\section{Testemunhos: limites à liberdade de expressão para proteção da organização social}

"Ouvimos todos conturbados e deixamo-nos ficar calados muito tempo. O pai andava para trás e para a frente, taciturno, sombrio, até que lhe perguntei: 'Mas tu achas possivel que envenenem as pessoas com gás, que as queimem, e que utilizem os seus cabelos, a pele, os dentes?' $E$ ele, que contudo vinha de Dachau, respondeu: 'Não, nem pensar. Um Thomas Mann não devia dar fé a esses horrores.' Mas afinal era tudo verdade: poucas semanas depois tivemos as provas e convencemo-nos" (Levi, 2008:193)

A primeira diferenciação social é a de género sexual. A primeira hierarquização social também. Parece-nos natural desqualificar quem não tenha um papel masculino. Como as crianças, ou os velhos, a quem a liberdade de construir género à sua vontade é simplesmente negada, não reconhecida ${ }^{1}$.

1 Crianças com dois anos insistem em viver segundo género não atribuído, contrariando o género atribuído e ensinado pelas figuras cuidadoras. O facto de isso ser tratado não pela ciência (Saleiro, 2010), mas por movimentos cívicos de pais, que reclamam liberdade de autodeterminação de género, sem pareceres médicos, dá-nos uma ideia da profundidade do viés cultural da nossa civilização. 
Entre cientistas sociais não é consensual a existência da questão de género. Naturaliza-se e nega-se o fundo social das discriminações.

Mais do que um defeito epistemológico, a omissão da importância fundamental das questões de género - questões remetidas para especialidade, como todos os assuntos cujo tratamento implique a denúncia das limitações das teorias sociais e dos princípios da organização social - resulta de um obstáculo emocional. Obstáculo que as ciências sociais, tal como o senso comum, têm dificuldade em reconhecer.

Habituados ao estado de guerra civil em torno das identidades de género, tomamo-la como natural. Acusam-se alguns dos agressores. Iliba-se o estado de guerra. Não se é capaz de imaginar a prevenção (Dores, Pontes, \& Loureiro, 2016). Não sabemos combater as condições sociais que reproduzem as situações violentas, por exemplo, a misoginia, o patriarcalismo e a estigmatização envolvidos nos crimes sexuais (AAVV, 2013). Os fundamentos milenares sobre os quais a civilização ocidental se construiu.

As evidências, como a misoginia social que faz vítimas tantas mulheres às mãos dos seus homens (ou melhor, os homens que entendem ter de defender a posse dessas mulheres), não têm sido suficientes para fundamentar as descrições denuncias do que seja, na verdade, a organização social. O segredo social impõe limites à liberdade de expressão e de compreensão: a proteção dos fundamentos emocionais, sociais, dogmáticos, da organização social. Esse limite está incorporado. Por isso, cabe às ciências sociais descobrir esses limites e procurar saber como será a vida para lá deles. Tomemos três exemplos:

\section{Caso 1.}

No primeiro discurso denunciou disfuncionalidades das prisões (na biblioteca, na recepção de livros do exterior, entre outras). Com o segundo discurso explicou ter sido vítima de oito investidas com arma branca por parte do ex-marido. A quem visitou na cadeia, apoiando-o nos esforços para retomar a sua vida. Numa rara ação de justiça restaurativa.

Houve um hiato discursivo entre a apresentação das questões do poder (as disfuncionalidades do sistema prisional) e as questões do cuidado (apoiar um preso). Hiato explicável pela separação entre o mundo social do poder, da voz, do masculino e do de cima, e o mundo dos cuidados, dos segredos, do feminino e do de baixo: o mundo da ação legítima e o mundo alegadamente irrelevante das vítimas, eventualmente mediado pelas artes. Há o mundo dos protagonistas (Alexander, 2011), da certeza dos poderes de agência (Archer, 2007); e há o mundo das mulheres batidas, dos homens presos, das denúncias de violação de direitos humanos. 
Hiato explicado pragmaticamente pela testemunha que, ao mesmo tempo, juntou e separou os dois discursos: conseguir o divórcio e a divisão de bens ao menor custo possível levou-a a ter interesse em fazer um acordo. O autocontrolo construído em anos de prática de meditação, deu-lhe capacidade. A dominação espiritual sobre o homem que tentou o homicídio foi uma operação bem-sucedida. Permitiu a pacificação dos conflitos, interiores e sociais. Mas é melhor conseguida por quem seja capaz de incorporar uma cultura marginal, orientalista, pacifista.

A filha do casal recusa-se a manter qualquer relação com o pai e mantém um conflito de opinião com a mãe a respeito da figura do pai. Diz ela que desde os seus 12 anos percebeu a perversidade do comportamento do pai. Pergunta-se como a mãe não se protegeu a ela e a si contra isso? Como o visitou na prisão e o apoiou?

A filha tende a culpabilizar não apenas o agressor mas também a vítima: repugna-lhe o contacto da mãe com o criminoso. São reações emocionais vulgares na cultura ocidental, usadas e desenvolvidas processualmente pelo sistema criminal penal.

A percepção das relações sociais utilizada pela filha, imaginando coerência, premeditação, autodeterminação individuais, nos termos da tradição jurídica ocidental de responsabilização individual pelo respeito dos contratos, é incompatível com a justiça restaurativa. A crítica militante da mãe é de que todos erramos e todos merecemos uma segunda oportunidade. Não apenas para benefício de quem cometeu crimes, mas, igualmente, para benefício da sociedade e, em primeiro lugar, das vítimas. Estas podem deixar de viver o trauma, o mau estar e o estigma associados aos crimes. Crítica interpretada pela sua amiga, pessoa particularmente religiosa, como uma oportunidade de reconciliação do casal. Isto é, de respeito pelo matrimónio, e da hierarquia misógina.

De facto, quando se fala de violência de género, quem se recorda de ouvir e dar crédito a um testemunho de uma vítima? São precisos psicólogos e criminólogos para explicar, conforme lhes interesse, aquilo que possa ser a experiência que nunca viveram. Ou que viveram em segredo (Foucault, 1999a).

\section{Caso 2.}

Trabalhadores sociais encarregues de integrar jovens em risco convocaram uma reunião clandestina sobre a violência policial. Os organizadores sabiam que a publicidade os tornaria desempregados. Nessa reunião foi dito que a Assembleia Municipal atendia problemas decorrentes da pobreza da maioria dos habitantes daquela zona residencial. Porém, o testemunho do quotidiano e arbitrário ataque da polícia às pessoas do bairro estava fora de questão. Havia 
a certeza de o acolhimento na Assembleia Municipal ser de ultraje e repúdio, com consequências punitivas.

As polícias comportam-se, em certos bairros populares, como em estado de guerrilha; de forma impensável para quem resida em bairros de classes média e superiores. As referências a tal estado de coisas são automaticamente entendidas, benevolamente para o Estado e a polícia, como uma necessária reação contra os perigos que representam certas partes da sociedade. Os mais pobres são associados ao perigo social pela simples razão de serem pobres, mesmo por teorias radicais e crítica (Haiven, 2014:121). Por se deixarem seduzir - como todos os outros - pela propaganda da publicidade, sem conseguirem dominar o vício aquisitivo assim estimulado. Esta ideia está consagrada em tese sociológica clássica (Merton, 1970).

O mecanismo de segredo social explica como a própria população alvo dos estigmas é levada a acreditar haver um problema consigo. A culpa/vergonha de ficar do lado dos estigmatizados, ajuda a explicar o silêncio das testemunhas. Nem os trabalhadores sociais nem as vítimas da violência policial quotidianamente organizada têm condições de apresentar publicamente - dificilmente o fazem entre si - a opressão policial. Se o fizerem, quando o fazem, são classificados como potenciais fora da lei, como defensores de crianças e jovens pré-delinquentes, como minorias de oposição numa época sem oposição possível (Marcuse, 1991b).

As crianças, desde a idade pré-escolar, com idades de 4 anos, sentem a presença da polícia no bairro como uma ameaça. Quando estão nas escolas, contam os professores, obrigam-nos a mudar o plano de atividades para um modo que os possa acalmar e tranquilizar do estado de exaltação em que ficam por saberem a polícia por perto. Desde tenra idade, milhares de crianças e jovens aprendem a ser humilhados no seu íntimo, em segredo. Com consequências psicológicas e sociais que estão por avaliar. Os sintomas de stress pós-traumático foram durante décadas simplesmente negados pelos militares, apesar das evidencias na vida dos veteranos. Sintomas que não são estudados nas populações sujeitas à pressão policial quotidiana.

$\mathrm{Na}$ reunião sobre violência policial referida, o único jovem do bairro que se pronunciou perguntou que esperança poderia ter de ver invertida a situação, se os discursos dos ativistas presentes referiam, por um lado, a impunidade da violação das leis por parte dos polícias, a cumplicidade das suas chefias e das instituições judiciais e políticas, e, por outro lado, o combate proposto era enviar às autoridades competentes denúncias sobre casos concretos de abuso de autoridade, para registo?

De facto, quando se fala de violência nos bairros, quem se recorda de ouvir e dar crédito a um testemunho de uma vítima? São precisos psicólogos e criminólogos para explicar, conforme lhes interesse, aquilo que possa ser a experiência que nunca viveram. Ou a viveram em segredo. 


\section{Caso 3.}

Quando o seu diretor perguntou a Wieviorka pelas razões por que se interessava pelo estudo do terrorismo, ele sentiu que a sua carreira académica ia ser bloqueada. Não foi o caso. Mas contou o episódio num congresso, quando era presidente da Associação Internacional de Sociologia.

Qualquer estudioso das prisões poderá testemunhar a diferença de tratamento institucional e pessoal que lhe é dirigido, caso opte por refletir sobre denúncias de maus-tratos e de arbitrariedades - obviamente banais nas prisões. Wacquant sentiu que a denúncia que fez do estado penal norte-americano lhe fechou muitas portas. Numa palestra sobre a nova área de investigação de radicalização e terrorismo, ambos os participantes concordaram em afirmar que os estudiosos que procuram enquadrar ambos os problemas nas relações históricas entre as civilizações muçulmana e ocidental não eram financiados (Pinéu \& Leuprecht, 2015).

A produção sociológica, inevitavelmente, sofre pressões para se conduzir a favor do modo dominante de organização. O estranho é essas pressões não serem denunciadas como entorses à liberdade de crítica que se diz ser a base da organização científica. São os próprios colegas a usar entre si essas pressões, como formas de luta ideológica, em que aqueles que são apoiados pelo status quo, naturalmente, têm vantagem. Por outro lado, como seria possível as ciências sociais estarem isentas da reverência exigida pelas organizações a todas as pessoas? Como poderiam viver os cientistas sociais fora dos constrangimentos sociais comuns?

A liberdade de expressão em ciência está condicionada de tal modo que o estudo da face, o principal instrumento de apresentação e interação social, está praticamente abandonado (Dores, 2017). O que discrimina, em particular, os surdos, que usam a face como forma de composição da língua gestual que usam. Discriminação que reforça a estigmatização organizada pelos estados modernos contra a surdidade, a cultura surda (Ladd, 2013). Assunto tão ignorado pelas teorias sociais como o dilema entre o desejo do desenvolvimento moderno e os genocídios para o concretizar.

Perante a intensa concentração social de atenções nas lutas pelo poder, evidente na comunicação social, a tomada de consciência das responsabilidades humanas de prestar cuidados é desqualificada. O trabalho voluntário torna-se apenas útil em situações de emergência, de exceção (ou como entretenimento dos próprios voluntários) e por tempo limitado ou sistematicamente interrompido; trabalho quotidiano escamoteado, dissimulado, desqualificado, incluindo pelas ciências sociais.

A teoria social depende dos seus financiadores e das hierarquias (Coser, 1956:27), cuja misoginia e mania hierarquizante endémicas, mais ou menos dissimuladas, também estão presente nos centros de investigação. Será possível sair deste efeito de retroação entre a sociedade e a teoria social, entre a 
sensibilidade comum e os critérios de avaliação científica, entre a crítica e o politicamente correto?

\section{Antropologia jurídica}

"Fazer de cada um de nós um 'homo juridicus' é a maneira ocidental de ligar as dimensões biológicas e simbólicas constitutivas do ser humano. O Direito religa a infinidade do nosso universo mental à finitude da nossa experiência física e é isso que cumpre em nós a função antropológica da instituição da razão" (Supiot, 2005:5), tradução APD.

O idealismo separa o mundo virtual do mundo prático, o trabalho intelectual do trabalho manual, o direito da sociedade, aquilo que devia ser daquilo que é. O que o caracteriza o idealismo, relativamente ao empirismo ou ao materialismo, porém, não é isso; é a presumida independência e superioridade ontológica das ideias sobre a matéria: representação ideológica da discriminatoriamente construída superioridade de quem tenha a possibilidade de desenvolver ideias próprias relativamente à maioria da população de presumidos seguidores de ideias comuns. Os patrícios romanos, os senhores medievais, os reis absolutistas, os burgueses livres, os santos, os artistas livres, os cientistas, os empresários, os dirigentes, estão entre os raros que podem aspirar a entrar na história. A iniciativa de plebeus acaba mais vezes representada em chacinas do que em glória aos seus nomes. Com a notável exceção das identidades colectivas mitificadas e irracionais (Girard, 1978), de que a ideia de nação é herdeira.

A história da civilização ocidental tem um aspecto de democratização, de mimetismo, das massas relativamente àqueles que têm tempo para cultivar a sua vida virtual, as suas ideias e os seus ideais (Elias, 1990; Foucault, 2004). Seja no aspecto (f)útil, da higiene diária e da cosmética, das convenções de vestir ou do desporto, seja no aspecto intelectual, nas escolas, religiosas e laicas, na ciência e tecnologia, no uso das instituições.

A cultura e a antropologia ocidentais elaboram-se, construíram-se, desenvolveram-se, sobre esta divisão dialéctica entre o que existe independentemente de nós, a natureza, e aquilo que, independentemente de tudo, criamos com a mente. Divisão entre quem trabalha e não pensa, e quem pensa e não trabalha. Divisão entre os civilizados, urbanos, e os camponeses ou selvagens. 
Figura 1. Representação da estrutura base da organização social

$$
\text { Lutas pelo poder }
$$

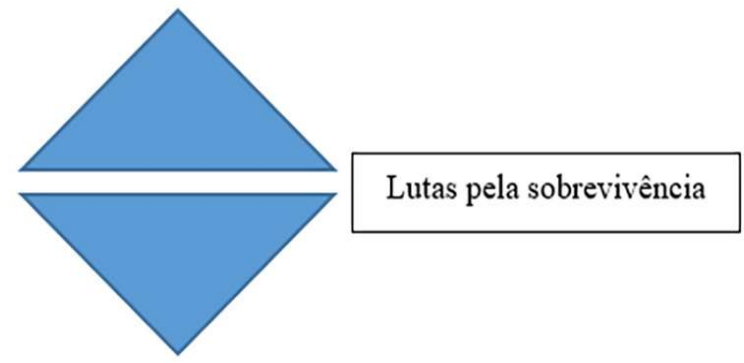

O sacrifício, sob diferentes formas, toca a todos: é o desconforto próprio das situações de afastamento em relação à média da condição humana. Os sacrifícios heroicos, dos dirigentes, são publicitados e glosados pela glória, conseguida ou falhada. Ao contrário, os sacrifícios de sobrevivência são alvos de segredo social, são coisas privadas, como se estivessem vocacionados para olhar apenas para cima.

Gregory Clark (2014) descobriu uma lei da mobilidade social representada por uma constante, que significa, na prática, uma tendência para a igualdade social, mas tão lenta que acaba por tornar as desigualdades de oportunidades entre famílias praticamente recorrentes. A figura 1. representa, ao mesmo tempo, o esforço organizado das sociedades para manterem essa desigualdade e um dos modos como o fazem: distinguem, sem contraditório que não seja anedótico, diversos géneros de pessoas, em função do sexo, da sexualidade, da capacidade de expressão, da riqueza, naturalizando essas distinções: quem nasce mulher ou com limitações de expressão ou em casa pobre só excepcionalmente pode esperar oportunidade nas lutas pelo poder.

Essa constante de Clark é válida para todas as sociedades estudadas, no ocidente, no oriente e em África, como é válida para sociedades pré-modernas para as quais o autor obteve informações estatísticas. Conclui haver um qualquer fundamento genético, ancestral, que explicará tal constante. Se a organização social não for geneticamente determinada, o fundamento material da constante de Clark poder ser a estrutura social ancestral: a misoginia elitista e dissimulada. O que explica a diferença de representar a sociedade e a organização em forma de losango, como na figura 1., em vez de como um triângulo, como é vulgar, considerando apenas as lutas pelo poder e olvidando as lutas pela sobrevivência.

Habermas (1987) faz assentar na esfera da experiência, na vida quotidiana de reprodução social, as modernas esferas económica e estatal. Porém, como outros cientistas sociais, seguiu o direito moderno que, ao mesmo tempo, penetra e regulamenta histórica e paulatinamente cada vez mais aspectos da esfera da experiência, e estabelece o direito de propriedade e de privacidade, em favor 
das classes dominantes. Abandonando, como vimos as ciências sociais fazer, as atividades de reprodução social à responsabilidade individual e anti-solidária, sem questionar as causas das desigualdades de oportunidades, tomadas como espontâneas, naturais e inelutáveis (Rawls, 1993).

Há uma grande dose de resignação na abordagem moderna das desigualdades sociais produzidas pela civilização (Nunes 2003:79-80). São tratadas como custos a pagar por quem não disponha de recursos de poder e, por isso, mereça pagar esses custos em beneficio das melhorias sociais vindouras (Novak, 2000). O sacrifício é reclamado à maioria, em nome da sustentabilidade do espírito heroico dos raros seres humanos de mérito.

A selvajaria moderna, presente em tantos genocídios, guerras, na indiferença organizada perante a pobreza, incluindo de crianças e suas mães, em nome da exploração económica e política da Terra e das suas populações, representa-se como o cúmulo das possibilidades de convivência urbana (Voltaire, 1795). Dissimula e faz segredo social da recorrente persistência moderna das práticas sacrificiais ancestrais, como nos diferentes modos de opressão das mulheres e crianças, através de mutilações genitais, abusos sexuais, bater por amor, etc.; mas também de muitos outros modos, como o tratamento degradante de pessoas com necessidades especiais, incluindo os doentes ou idosos. De que a exploração do trabalho é uma expressão.

A diferenciação social permite, a quem se sacrifica a cumprir funções cimeiras, viver sem pensar na sobrevivência quotidiana. Ainda que os melhores espíritos possam defender tolerância para com os desvalidos - dita sensibilidade social - ela é voluntariosa, opcional. Não é prioritária, como seria se fosse economia ou política. Goffman (1986) descreve os trabalhadores sociais como filantropos: quem tem a rara disposição e o raro conhecimento capazes de passar as fronteiras sociais entre a sociedade legítima (leia-se económica e politicamente influente e defendida) e a dos excluídos. Mundos social, laboral e do crime, imaginados como secundários, marginais, dependentes, incapazes de iniciativa: submundos de onde, de quando em vez, surgem desafios para os poderes estabelecidos - causados pela maldade, pela loucura, pela falta de educação de anarquistas, comunistas e criminosos (Foucault, 1999a) - a que é preciso por cobro, para reestabelecer a ordem do segredo sobre tais vidas ou tais aspectos da vida social.

Os melhores espíritos defendem a diminuição do peso dos sacrifícios, sem contestar a versão ideológica oficial de o mundo marginal ser minoritário e apenas culpa de quem lá se encontra. Realisticamente, os efeitos discriminatórios da organização social são efetivamente incorporados e reproduzidos pelas próprias vítimas. Primo Levi, nos campos de concentração nazis, dá-nos conta do desenvolvimento do orgulho em ser bom prisioneiro (2013:180).

Os limites sociais à liberdade de expressão são usados para reforçar os princípios básicos da organização social. Tais limites são frequentemente 
incorporados, por algozes, vítimas, comunicação social (Dores, 2013), público e sociedade. Excepcionalmente, no exercício de liberdades reflexivas bem orientadas, isto é, socialmente organizadas, é possível exercitar a liberdade de expressão tão ampla que seja capaz de denunciar a persistência das violências, das desigualdades de oportunidades, da resistência à equalização social que produz a permanência das elites, das estratégia de dissimulação que usam as características mentais dos seres humanos (limitado número de focos de atenção, susceptibilidade à submissão por razões de solidariedade e de economia de energias, prazer sádico ao testemunhar o sofrimento dos outros (Collins, 2013), etc.).

São excepcionais os momentos em que se produz direito; direito à liberdade de expressão. Momentos fundadores de novas ordens sociais, por exemplo através de constituições sobre como deveriam funcionar organizações e sociedades. Ou momentos de adopção de usos normalizados de tecnologias sociais (Supiot, 2002). O direito das maiores liberdades não é resultado da racionalização moderna. É o inverso: a racionalização depende do direito previamente estabelecido. Reclama, antes, por uma antropologia jurídica capaz de reconhecer o direito como uma forma de sociabilidade ancestral, prévia à invenção da escrita; forma de estruturar a paz entre as pessoas e as suas relações com a natureza, através de consensos tácitos sobre os modos de usar os conhecimentos e os instrumentos disponíveis. Esperança de ordem, produtividade, mas também de capacidade de organizar a transformação social.

$\mathrm{O}$ direito moderno, primeiro, tornou-se refém da propriedade privada; integrou o estado montesquiano, ocupando o seu lugar em solidariedade com os parlamentos e os governos, cada um com a sua independência. Separou-se do direito natural, não escrito, que se tornou direito partidário, softlaw, como hoje são os direitos humanos. Depois, como refere Habermas, começou a penetrar cada vez mais na esfera da experiência, conflituando e substituindo o direito anteriormente vigente. Mas sem ser capaz de (ou estar interessado em) pôr em causa a base ancestral de organização social.

\section{Sacrifício e o segredo social}

"O facto da vasta maioria da população aceitar, e seja levada a aceitar, este [tipo de] sociedade não a torna menos irracional ou menos repreensivel" (Marcuse 1991:xliv)

Os seres humanos sacrificam-se por ideias sociais incorporadas em cada um, como identidade íntima. Por exemplo, sacrificam-se quando resistem em posições sociais desagradáveis, marginais (Dores, 2010b), ou aceitam situações de integração social contra os seus próprios interesses, como na escravidão, 
para manterem posições de diferenciação e hierarquia capazes de os protegerem da vida nua, a temível desproteção inconcebível e radical de isolamento e alheamento sociais (Agamben, 1998).

Exemplos de sacrifícios são as pessoas dissimularem a sua orientação sexual desconforme à heterossexualidade; ou, nas experiências de Milgram, praticarem tortura para ter a hipótese de manter uma posição social intermédia; ou, quando os presos, inclusive nos campos de morte, organizam hierarquias (Levi 2008:67).

As pessoas aprendem a dizer que gostam da sorte que lhes calhou em vida ou no trabalho. Fazem-no eventualmente pelo seu conteúdo, mas também para valorizar a conformidade e minimizar os conflitos. Identificam-se com os respectivos papéis sociais. Evitam assim o risco de anomia: a falta de capacidade anímica para viver a vida; a inanição criada pelo sentimento de falta de sentido da vida.

Sacrificam-se os pais que pagam a vida escolar dos filhos, sem terem condições para o fazer e manter uma vida digna ao mesmo tempo, para que o estatuto social da família possa dar sentido à falta de sentido da vida atual. Sacrificam-se os voluntários ou familiares que dedicam a sua vida, ou parte dela, a cuidar de outros. Sacrifícios que também dão prazer e estatuto, como no caso das pessoas religiosas, trabalhadores sociais ou ativistas dos direitos humanos. Sacrifícios eles próprios organizados segundo o modelo da diferenciação e da hierarquização.

Sacrifícios no feminino, como os cuidados domésticos socialmente invisíveis e desconsiderados, apesar da sua quantidade e importância básica para a sobrevivência da espécie. Sacrifícios no masculino, no sector militar, como o fazem os heróis. Heróis que podem substituir e representar povos inteiros, tomando para si os interesses de que tantas vezes ignoram o alcance, mas com os quais são solidários. O risco de morte física é compensado pela eventual glória eterna.

Sacrificam-se também os dirigentes, quando fazem depender as respectivas vidas dos interesses sociais gerais e do escrutínio, nem sempre amigável, dos subordinados e das populações. Embora se tenham organizado de modo a reduzir as práticas de fazer rolar cabeças, os dirigentes sacrificam-se, arriscam, à sua maneira, independentemente dos privilégios que lhes sejam concedidos e os sistemas de segurança que os isolem do resto da sociedade.

O hedonismo moderno e consumista celebra o desejado fim dos sacrifícios. Porém, mesmo os principais beneficiários da modernidade têm que trabalhar muito e continuamente para que as crises não subvertam a hierarquização social e as ideologias dominantes, como as que nos asseguram que o crescimento do PIB e dos mercados resolve todos os problemas. Na prática, os sacrifícios continuam aí. As penas, como notou Foucault, deixam de ser públicas e passam para trás de altos muros penitenciários. No caso dos trabalhadores 
livres, sacrificam-se para terem direito a sobreviver, ter férias e reforma, em troca da sua colaboração e da abstinência de comandar as suas próprias vidas. Estão sacrificialmente disponíveis para se deslocarem para longe das suas residências, como os professores, ou para trabalhar em turnos que os impedem de ver as famílias, ou para suportar ambientes de trabalho opressivos, como os que degeneram em suicídios ou acidentes de trabalho.

As tecnologias produzidas e usadas pelos trabalhadores servem para manter a hierarquização social e a representação das populações, sociedades, povos, como elementos naturais, isto é, susceptíveis de exploração, em nome da autoridade concedida religiosamente aos ocidentais pela sua lei ancestral de justificação messiânica da dominação.

A confirmação moderna do valor das profecias sobre a Terra ser uma dádiva de Deus para os seus filhos, nas religiões do Livro, tomou um outro aspecto com os Descobrimentos e com o capitalismo. O revivalismo imperial moderno, agora a nível global (Camões, 1994), foi abençoado, digamos assim, pelo sucesso da empresa. Um dia, estimam os optimistas, com a integração social, até dos selvagens, os estigmas acabarão por desaparecer nas sociedades modernas; quando o ecumenismo se concretizar através dos benefícios da indústria e dos conhecimentos científicos. A narrativa da humanidade como irmandade, ou sociedade sem classes, apresenta a guerra e os genocídios recorrentes e continuados como uma fase transitória. O processo civilizacional (Elias, 1990; Morris, 2016) produz, ao mesmo tempo, a incorporação da repugnância perante a violência e estados mais militarmente poderosos de que há memória; produz o encobrimento noticioso das misérias quotidianas (Dores 2013), que levou o soldado Manning à tortura e à condenação judicial; encobre os mercados clandestinos de armas organizados pelos estados e a chantagem neocolonial (Perkins, 2004), que também afectam duramente as populações na Grécia e em Portugal, sacrificadas para ajudar a resolver magicamente a crise financeira de 2008, que ainda está por resolver.

Quem vive atualmente sob estigmas, ou sem acesso a recursos suficientes para viver em dignidade, sacrifica-se, nessa situação, à espera de, no futuro, poder ser cumprida a profecia da integração social plena: o pleno emprego, a irradicação da pobreza, o estado social, a paz, a abolição da pobreza e da fome, quem sabe, a abolição da morte. Sacrifícios feitos, também, sob ameaças de maior exclusão/repressão social ainda.

O segredo social tem a força suficiente para tornar o Holocausto invisível para quem o viveu, inclusivamente como vítima (Gemma, 2008). O segredo evita os sentimentos de medo e vergonha que a memória não pode ignorar (Levi 2008: 72,76). Segredo que ainda hoje é promovido pelos negacionismos. 
Figura 2. Bases da racionalidade ocidental

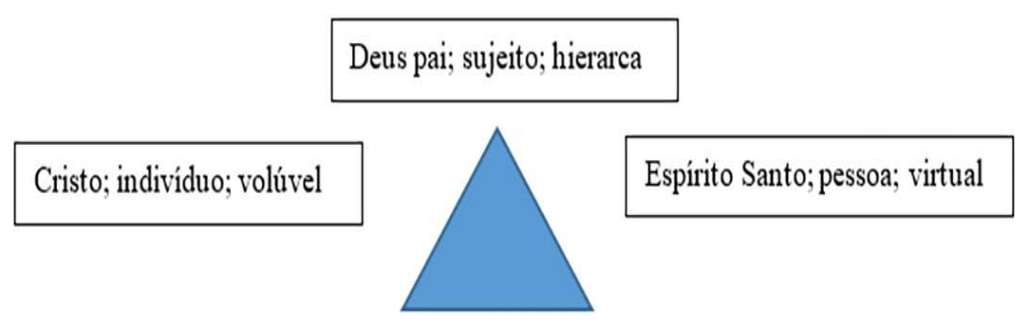

O segredo das teorias sociais está na recusa de admitir discutir os princípios essenciais da organização social. A recusa de admitir os dogmas religiosos na base da razão ocidental. O papel sacrificial que cabe às sociedades cumprir, no quadro da trilogia sagrada.

A divisão sociológica entre dimensões estanques, a política, a economia, a sociedade-cultura, fixada por Parsons a partir de Max Weber, hoje praticada nos jornais, através das respectivas secções, e nas ciências sociais, através da especialização das suas diferentes disciplinas, pode ser lida antropologicamente como a versão moderna de uma visão cristão da vida (ver figura 2.): poder político como Deus Pai, poder social como Deus Filho e poder económico como Espírito Santo (dinheiro, espírito do capitalismo, empreendedorismo).

“Esta montagem antropológica não pode assentar na ciência, pois a própria ciência resulta dessa montagem quando postula que o Homem é um sujeito de conhecimento capaz de se observar a si mesmo como objecto de conhecimento" (Supiot 2005:67, tradução APD). De facto, a natureza, aquilo que não pensa nem se autodetermina e apenas se dedica aos cuidados de sobrevivência, é o alvo das ciências naturais. As ciências sociais, por seu lado, imitam as ciências da natureza. Imaginam os indivíduos independentes da sociedade (dos sujeitos e das pessoas) estatisticamente classificados segundo métodos de posicionamento cartesianos e organizados mecanicamente em torno de lutas pelo poder. Quando o que se lhes deve pedir é que enriqueçam as ciências com as perspectivas que lhe faltam: as do sujeito que há em qualquer pessoa. 
Figura 3. Fundos discretos da racionalidade ocidental

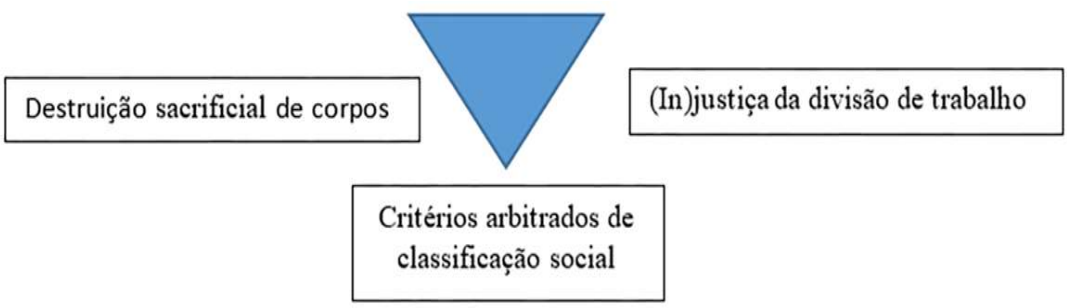

Tal como o senso comum, as teorias sociais enfrentam as dificuldades de encarar a montagem antropológica de que somos resultado e parte interessada. Preferimos tratar como excecional o Holocausto, evitando assim reconhecer a banalidade do uso do genocídio para abrir espaço e impor a modernização. Evitando, também, reconhecer a pandemia de abusos sexuais e violência contra trabalhadores e pessoas de género não dominante, a pretexto de serem violências privadas. Preferimos descrever os nossos tempos como tempos de igualdade entre trabalhadores e as elites, entre géneros, como se o estado de direito fosse capaz de transformar os melhores desejos doutrinários em boas práticas sociais. Preferimos naturalizar as discriminações de género e elitistas como dados de natureza sexual e de mérito inato.

A solidariedade, a tendência espontânea das pessoas para participarem na sociedade, como parte das suas necessidades existenciais, de reconhecimento e de construção identitária, é manipulada jurídica e culturalmente de modo a organizar, a favor das elites e em detrimento da maioria, a divisão de trabalho dos sacrifícios que tal solidariedade implica. Para o que os sacrifícios, ao mesmo tempo notórios e escamoteados, por exemplo dentro das penitenciárias e dos quartéis, sirvam de consolo e exemplo, negativo e positivo, para os sacrifícios quotidianos: estimulem a resiliência às injustiças sociais, em nome do bem-estar e da ordem social, do consumo e do crescimento da economia, da tranquilidade psicológica dos mercados.

\section{Notas}

“O que me preocupa não é o grito dos maus. É o silêncio dos bons”, frase atribuída a Martin Luther King

Como compreender o silêncio ensurdecedor que as teorias sociais dedicam à violência (Maleševi 2010:17; Wieviorka 2005:68), sobretudo à violência de Estado (Dores, 2014; Kuhn, 2016)? Como compreender a independência das teorias feministas relativamente 
às teorias sociais e à proliferação da híper especialização (Lahire 2012:347-351)? Como compreender a presença residual do debate sobre o que é a sociedade: um sistema de sistemas ou um conjunto de selves; um processo de delimitação de fronteiras ou a evolução histórica a partir de princípios de organização ancestrais?

A sociologia está focada em estudar as questões de poder (Therborn 2006:3; Lahire 2012:125). Concebe os seres humanos sobretudo como indivíduos envolvidos em lutas de poder. Não os trata com a densidade antropológica de sujeitos e pessoas que usam diferentes identidades sociais, consoante a situação (Dores, 2010a). Não está em condições de compreender nem as transformações das pessoas - e das sociedades - nem as bases sociais dessas transformações: o magma de relações comunitárias, as redes de interação, que cuidam de manter a vida de cada um, movidos pela complexa tensão entre a vontade social de igualdade e a reprodução das identidades diferenciadas e das elites. A vida privada quotidiana é, ao mesmo tempo, um segredo social e um limite do conhecimento sociológico. Segredo evidente na falta de protagonismo do tema do sacrifício, de que o estudo do suicídio de Durkheim e a sua descontinuidade é exemplo.

A moderna luta de classes é, afinal, a parte visível de um iceberg (figura 1.) que separa políticos e operacionais, casa grande e sanzala, ricos e pobres, honra e trabalhado, senhores e leigos, vozes e silêncios, demagogia e sacrifícios. O que fabrica o iceberg social é a organização social arbitrada por uma civilização sintetizada em normas socialmente construídas (figura 2.), constituindo-se na principal fonte de dissimulação da misoginia e do elitismo (Shahak, 1994), ancestral e persistente (figura 3.).

Uma mulher vítima de abusos simplesmente prefere, com enorme frequência, evitar denunciá-los. Quando o faz, mesmo em sociedades que os criminalizam, é muito frequentemente alvo de processos de revitimização, eventualmente conduzidos de forma institucional. O mesmo se pode dizer dos habitantes de bairros populares alvo da atividade policial. Sociólogo que se depare com tais situações e sobre elas se queira debruçar enfrentará censuras internas e externas na profissão.

A ideia de empreendedorismo, por exemplo, expressão em moda para justificar a necessidade social e as vantagens pessoais dos sacrifícios, a par da atribuição da singular responsabilidade individual da posição social de cada um, faz segredo da mortalidade das iniciativas empresariais e da predação a que estão sujeitas pelas empresas dominantes, qual cardume de sardinhas guiadas por tubarões, reduzindo a esmagadora maioria dos potenciais empreendedores a trabalhadores precários. A modernidade usa sistemas de sociabilidade usados também por sociedades tradicionais, que fazem do espírito de sacrifício símbolo e prática de solidariedade e entrega a identidades sociais manipuladas, na tropa como nas websummit. Embora seja clara a manipulação, cuja finalidade é manter a hierarquia e grupos sociais alvos de estigma da indignidade, tudo se passa 
como se essa vontade colectiva fosse um segredo. Raros querem tomar consciência disso e quando o fazem ressentem-se da violenta oposição e repugnância social.

A teoria social não tem tido nervo para chegar à vida íntima das sociedades. Entusiasmada com a diferença entre a sociedade moderna e as outras, faz segredo dos sacrifícios, como genocídios, explorações, riscos ambientais, ou as violências quotidianas como as citadas neste artigo, mesmo quando os regista. Não considera o facto de as sociedades modernas serem resultado da evolução da espécie humana e, portanto, fundadas num magma bio-cultural-doutrinário ancestral que explica a disposição sacrifício-segredo que legitima a persistências das mesmas famílias em posições de poder (Clark, 2014; Louçã, Lopes, \& Costa, 2014).

Estudar a profundidade em que a diferenciação e a hierarquização social estão incorporadas é uma tarefa hercúlea (Silva, 2003). As ciências sociais sacrificam, também elas, a ânsia de procura da verdade, submetendo-se aos segredos sociais que se abatem sobre os próprios sacrifícios.

A modernidade democratiza e esconde os sacrificados, por exemplo, nas prisões, nas fábricas ou nas escolas. O valor do testemunho do diretor de cadeia ou do polícia é incomparável com o do prisioneiro ou alegado criminoso. De forma menos radical, o mesmo se passa em qualquer outra organização: a hierarquia e o género marcam diferenças de legitimidade dos testemunhos, com bastante independência da verdade dos factos. As massas, assim disciplinadas, como diria Foucault, comportam-se como carneiros ou burros com palas laterais, encantados pela propaganda, como na história do flautista de Hamelin, dos irmãos Grimm. Por exemplo, quando consomem aquilo que se lhes apresenta, apesar dos modos irracionais e violentos com que a produção é feita, no abuso de crianças, mulheres, trabalhadores, animais e meio ambiente. No quotidiano, embora circule informação suficiente para todos saberem o que se passa, a força do segredo social é tal que nos contentamos com o facto de haver quem se sacrifique mais do que nós: nas elites (quando alguém cai em desgraça) ou na pobreza, representada como vivendo em países distantes e inacessíveis. Resignamo-nos, em auto administrada liberdade, a viver no melhor dos mundos possível, mantendo sobre o assunto, incluindo nas ciências sociais, um manto de segredo social fundado na repugnância (biológica?) sempre que se tenta discutir a (i)moralidade ancestral dos fundamentos jurídicos da misoginia e da divisão de géneros, do elitismo e dos privilégios, e da cobertura estatal à normalização e expansão globais das injustiças, em nome do crescimento económico.

\section{Referências bibliográficas}

AAVV, (2013), Transformative justice, S. Francisco, disponível em: http://www.generationfive. org [consultado em 12.10.2016]. 
AGAMBEN, Giorgio (1998 [1995]), O Poder Soberano e a Vida Nua, Lisboa, Editorial Presença. ALEXANDER, Jeffrey C. (2011), Performance and Power, NY, Polity.

ARCHER, Margaret S. (2007), Making our Way through the World, Cambridge, Cambridge University Press.

BLUMER, Herbert, (1981), “George Herbert Mead”, em B. Rhea (Ed.), The Future of Sociological Classics, Allan \& Unwin.

CAMÕES, Luís de (1994 [1572]), Os Lusíadas, Porto, Porto Editora.

CLARK, Gregory (2014), The Son Also Rises, Princeton and Oxford, Princeton University Press.

COLLINS, Randall (2013), Micro and Macro sociological causes of violent atrocities, Sociologia Problemas e Práticas, (71), 9-22.

COSER, Lewis (1956), The Functions of Social Conflict, NY, Free Press.

DORES, António Pedro (2010a), Espírito de Proibir, Lisboa, Argusnauta.

DORES, António Pedro (2010b), Espírito Marginal, Lisboa, Argusnauta.

DORES, António Pedro (2013), “A análise jornalística torna irreconhecível a densidade da vida”, Revista Angolana de Sociologia, (11), 35-50.

DORES, António Pedro (2014), "Violence in society”, Pensamiento Americano, 7(13), 144-162.

DORES, António Pedro (2017), Oferecer a face - tabus e caminhos das ciências sociais, Beau Bassin, Novas Edições Académicas.

DORES, António; PONTES, Nuno; \& LOUREIRO, Ricardo (2016), Manifesto for a new penal culture, Rome.

ELIAS, Norbert (1990), O Processo Civilizacional (Vol I e II) (1a edição), Lisboa, D. Quixote.

FARA, Patricia (2009), Science: a Four Thousand Years History, Oxford, Oxford University Press.

FOUCAULT, Michel (1999a), Les anormaux, Paris, Gallimard, Le Seuil.

FOUCAULT, Michel (1999b [1977]), Microfísica do Poder, Rio de Janeiro: Graal.

FOUCAULT, Michel (2004 [1981]), A Hermenêutica do Sujeito, São Paulo, Martins Fontes.

GEMMA,Zalmen (2008), Enel corazón del infierno - documento escritopor un Sonderkommando de Auschwitz - 1994, Barcelona, Anthropos.

GIRARD, René (1972), La Violence et le sacré, Paris, Grasset.

GIRARD, René (1978), Des Choses Cachées Depuis la Fondation du Monde, Paris, Éditions Grasser et Fasquelle.

GOFFMAN, Ervin (1986), Asylums - Essays on the social situation of mental patients and other inmates, NY, Anchor Books.

HABERMAS, Jürgen (1987 [1981]), “Tendencies toward Juridification”, em The theory of Communicative Action ([1981], pp, 356-373), Cambridge, Polity Press.

HAIVEN, M. (2014), Crises of Imagination, Crises of Power - capitalism, creativity and the commons, Winnipeg e NY, Fernwood Publishing e Zed books.

KUHN, Michael (2016), How the Social Sciences Think about the World's Social - Outline of a Critique, Stuttgard, Ibidem.

LADD, Paddy (2013), Em Busca da Surdidade 1 - Colonização dos Surdos, Surd'Universo.

LAHIRE, Bernard (2012), Monde pluriel, Penser l'unité des sciences sociales (Couleur de), Paris, Seuil.

LEVI, Primo (2008), Os que sucumbem e os que se salvam, Lisboa, Teorema.

LEVI, Primo (2013), Se isto é um homem, Lisboa, Teorema.

LOUÇÃ, Francisco, LOPES, João Teixeira, \& COSTA, Jorge (2014), Os Burgueses - quem são, como vivem, como mandam, Lisboa, Bertrand.

MALEŠEVI, Siniša (2010), The Sociology of War and Violence, Cambridge, Cambridge University Press.

MARCUSE, Herbert (1991a [1964]), One-Dimension Man, London, Routledge \& Kegan. 
MARCUSE, Herbert (1991b [1964]), “The New Forms of Control”, em One-Dimension Man, pp, 3-20), London, Routledge \& Kegan.

MERTON, Robert (1970), “Estrutura social e Anomia”, em Sociologia - Teoria e Estrutura (pp, 203-233), S. Paulo, Mestre Jou.

MORRIS, Ian (2016), Guerra! Para que serve? - o Papel do Conflito na Civilização, dos Primatas aos Robôs, Lisboa, Bertrand.

MOUZELIS, Nicos (1995), Sociological Theory: What Went Wrong? - diagnosis and remedies, London, Routledge.

NOVAK, Michael (2000), “Defining Social Justice”, First Things, (108).

NUNES, Alevãs (2003), Neo-liberalismo e Direitos Humanos, Lisboa, Caminho.

PERKINS, John (2004), Confessions of an Economic Hit Man, Berrett-Koehler Publishers.

PINÉU, Daniel, \& LEUPRECHT, Christien, (2015), Mesa redonda "Radicalization Leading to Violent Extremism," Lisboa.

RAWLS, John (1993 [1971]), Uma Teoria de Justiça, Lisboa, Editorial Presença.

SALEIRO, Sandra (2010), “Transexualidade e Transgénero em Portugal: Dois 'vazios' em debate", In M, C, S, et Al, (Ed,), Sociedades Desiguais e Paradigmas em Confronto - vol IV (pp, 84-90).

SCOTT, James C. (2013 [1990]), A Dominação e a Arte da Resistência - discursos ocultos, Lisboa, Letra Livre.

SHAHAK, Israel (1994), Jewish History, Jewish Religion: the Weight of Three Thousands Years, London, Pluto Press.

SILVA, Gomes da, (2003), O Discurso Contra Si Próprio, Lisboa, Assírio e Alvim.

SILVA, Manuel Carlos (2009), Classes Sociais. Condição objetiva, identidade e ação coletiva, Vila Nova de Famalicão, Húmus.

SUPIOT, Alain (2002), “Travail, droit et technique”, Droit Social, 13-25.

SUPIOT, Alain (2005), Homo Juridicus - Essai sur la fonction anthropologique du Droit, Paris, Seuil.

THERBORN, Göran (2006), "Meaning, Mechanisms, Patterns and Forces: an Introduction”, In G, Therborn (Ed,), Inequalities of the World - New Theoretical Frameworks, Multiple empirical approaches (pp, 1-58), Londres, Verso.

VOLTAIRE, (s.d. [1795]), Cândido ou o otimismo, disponível em: http://www.dhnet.org.br/ direitos/anthist/marcos/hdh_voltaire_candido.pdf [consultado em 10,12,2016].

WACQUANT, Löic (2016), The puzzling return of prisons in the 21st Century, disponivel em: https://portal,oa,pt/media/119669/conferencia-internacional-as-nossas-prisoes-vfinal,pdf [consultado em 10,12,2016].

WIEVIORKA, Michel (2005), La Violence, Paris, Hachette Littératures. 